\title{
Differences in factors influencing the use of eRehabilitation after stroke; a cross-sectional comparison between Brazilian and Dutch healthcare professionals
}

\author{
Berber Brouns ( $\nabla$ b.brouns@lumc.nl ) \\ Leti van Bodegom-Vos \\ Leids Universitair Medisch Centrum \\ Arend J. de Kloet \\ Haagse Hogeschool \\ Thea P.M. Vliet Vlieland \\ Leids Universitair Medisch Centrum \\ Ingrid L.C. Gil \\ Rede SARAH de Hospitais de Reabilitacao \\ Lígia M.N. Souza \\ Rede SARAH de Hospitais de Reabilitacao \\ Lucia W. Braga \\ Rede SARAH de Hospitais de Reabilitacao \\ Jorit J.L. Meesters \\ Basalt Revalidatie
}

Leids Universitair Medisch Centrum https://orcid.org/0000-0003-2141-3624

Research article

Keywords: stroke, barriers and facilitators, implementation, rehabilitation, eRehabilitation, survey, intercultural

Posted Date: March 31st, 2020

DOl: https://doi.org/10.21203/rs.2.14597/v2

License: (c) (i) This work is licensed under a Creative Commons Attribution 4.0 International License. Read Full License

Version of Record: A version of this preprint was published at BMC Health Services Research on June 1st, 2020. See the published version at https://doi.org/10.1186/s12913-020-05339-7. 


\section{Abstract}

Introduction : To improve the use of eRehabilitation after stroke, the identification of barriers and facilitators influencing this use in different healthcare contexts around the world is needed. Therefore, this study aims to investigate differences and similarities in factors influencing the use of eRehabilitation after stroke among Brazilian Healthcare Professionals (BHP) and Dutch Healthcare Professionals (DHP). Method : A cross-sectional survey study including 88 statements about factors related to the use of eRehabilitation (4-point Likert scale; 1-4; unimportant-important/disagree-agree). The survey was conducted among BHP and DHP (physical therapists, rehabilitating physicians and psychologists). Descriptive statistics were used to analyse differences and similarities in factors influencing the use of eRehabilitation. Results : ninety-nine (response rate 30\%) BHP and 105 (response rate 37\%) DHP participated. Differences were found in the top-10 most influencing statements between BHP and DHP BHP rated the following factors as most important: sufficient support from the organisation (e.g. the rehabilitation centre) concerning resources and time, and potential benefits of the use of eRehabilitation for the patient. DHP rated the feasibility of the use of eRehabilitation for the patient (e.g. a helpdesk and good instructions) as most important for effective uptake. Top-10 least important statements were mostly similar; both BHP and DHP rated problems caused by stroke (e.g. aphasia or cognitive problems) or problems with resources (e.g. hardware and software) as least important for the uptake of eRehabilitation. Conclusion : The results indicate that the use of eRehabilitation after stroke by BHP and DHP is influenced by different factors. A tailored implementation strategy for both countries needs to be developed.

\section{Introduction}

\section{Contributions to the literature}

- To increase the uptake of eRehabilitation, this study identified and compared factors influencing the uptake of eRehabilitation in a western country, in which the most of the studies in this topic are performed, and a country in South-America, which may benefit most from the use of eRehabilitation.

- In Brazil, the most important facilitator for the use of eRehabilitation is support from the rehabilitation organisation. In the Netherlands, this was the feasibility of using eRehabilitation by patients.

- These findings underscore the importance of implementation strategies that are tailored to the context and wishes, needs and priorities of the end-users.

The rapid growth of digital health technology (1) provides efficient strategies for delivering rehabilitation while maintaining or improving effectiveness (2). Therefore, it may offer a solution for the increasing need for care, especially in stroke rehabilitation, where incidence, survival rates and healthcare costs are growing (3). Digital eRehabilitation programs offers an additional way of delivering conventional rehabilitation and can include physical and cognitive exercise programs, serious gaming, education (4-6) and e-consultations (7), delivered via a variety of information and communication technology (ICT) devices such as a computer, tablet and smartphone. eRehabilitation can be seen as an alternative way of providing all aspects of rehabilitation therapy, including intervention, maintenance activities, consultation, education, and training to clients at a remote location (4), and can included telerehabilitation (e.g. the provision of rehabilitation services to patients at a remote location using ICT), tablet-based therapy, and the use of commercially available devices like the Nintendo Wii $(2,4,5,8-11)$.

Randomized clinical trials and systemic reviews investigated the effects of eRehabilitation and showed multiple benefits of the use of eRehabilitation. eRehabilitation can decrease stroke-related impairments $(5,8,9)$, relieve healthcare professionals from manual labour, make rehabilitation accessible to larger number of stroke patients (2), continue therapy-related cognitive and motor activities during and after discharge (4), decrease chronic disability during and after sub-acute rehabilitation, and facilitate hometherapy $(10,11)$. Especially in regions with a paucity of socioeconomic resources and limited access to care, regions with the greatest burden of stroke worldwide (14), culturally-relevant eRehabilitation interventions are likely to be the most viable strategy to reduce burden (15). 
However, the use of eRehabilitation in daily practice lacks worldwide (17) and the uptake of eRehabilitation is hamper by many factors. This included lack of confidence with hardware or software $(18,19)$, fear of losing social face-to-face contact $(12,20)$ and lack of meaningful reimbursement $(7,21)$. In order to make eRehabilitation feasible, programs need to be tailored to the patients' needs and sufficient support of a helpdesk for ICT is a prerequisite (22). Studies performed in western countries concluded that eRehabilitation programs are generally considered feasible (5), however, in low- and middle income countries, future trails on the feasibility are needed (15). Furthermore, it has been shown that eRehabilitation interventions need to address culture-specific issues in order to be effective (23), however, eRehabilitation interventions for patients are rarely culturally-adapted (16).

To improve the uptake of eRehabilitation after stroke, the identification of barriers and facilitators influencing this use is needed (16). Most of the abovementioned research about barriers/facilitators in the use of eRehabilitation is performed in western countries (America, Canada, Australia, Europe), and as far as we know, no research is performed on the differences between western countries and other regions. Therefore, the aim of this paper is to describe the differences and similarities in factors influencing the use of eRehabilitation after stroke between Brazil and the Netherlands, countries with different cultures and healthcare systems.

\section{Methods}

To identify differences and similarities in factors influencing the use of eRehabilitation after stroke between Brazilian and Dutch healthcare professionals, cross-sectional study conducted in a medical specialist rehabilitation setting involved a one-time crosssectional online survey. This survey was developed based on the results of a preceding focus group study (24) and was conducted among Brazilian healthcare professionals (BHP) and Dutch healthcare professionals (DHP) working in stroke rehabilitation. The COREQ guidelines were used for adequate design of the focus groups (25) and STROBE statements were used for adequate sampling, analyses and reporting of the survey.

\section{Setting}

Brazil: Brazil has 209 million inhabitants, of which $70 \%$ has internet access. Brazil has a population density of 25 inhabitants $/ \mathrm{km}^{2}$ and gross domestic product of 8.2 US dollar/inhabitant. Data from a national prospective study indicate an annual incidence of 108 cases per 100,000 inhabitants. Stroke Care Guidelines are established involving pre-hospital treatment, intervention in acute stroke, and follow-up at rehabilitation centres $(26,27)$. Rehabilitation can take place on an outpatient basis, an inpatient basis, or during hospitalization. In all settings, interventions are delivered by multidisciplinary teams working in an interdisciplinary manner with active patient participation and family inclusion. Specialized professionals include physicians, nurses, social workers, physical therapists, occupational therapists, speech therapists, psychologists, hospital educators, physical education instructors, and nutritionists. The treatment and rehabilitation process are free of charge; the national health budget covers all costs.

Netherlands: The Netherlands have 17 million inhabitants, of which $95 \%$ has internet access. The Netherlands has a population density of 507 inhabitants $/ \mathrm{km}^{2}$ and a gross domestic product of 56.4 US dollar/inhabitant. The annual incidence of stroke in the Netherlands was estimated 107 cases per 100,000 inhabitants (28). Incidence and mortality rates decline as a result of better and faster treatment (29) and stroke burden in terms of the absolute number of people affected by stroke increase (30). About $10 \%$ of the stroke survivors follow multidisciplinary in or out-patient rehabilitation in a medical specialist rehabilitation setting (31), including physiotherapy, speech therapy, occupational therapy, psychology and a social worker, coordinated by a rehabilitation physician (32). A rehabilitation plan is made and evaluated during weekly team meetings, and patients and family are involved if needed. Rehabilitation consisted of individual and group exercise (32). Six months after stroke, on average $60 \%$ of the patients are community living again (33). Most costs are reimbursed by the healthcare insurance provider, with out of pocket costs for the patients of maximum €885,-.

\section{Study_population}

Inclusion criteria for both BHP and DHP were 1) at least two years of working experience in a multidisciplinary stroke team and 2) still actively treating stroke patients. Invited BHP included neurologists, physical therapists, occupational therapists, psychologists, nurses, social workers, speech therapists, hospital educators, and physical educators from the SARAH Network of Rehabilitation 
Hospitals. BHP working with stroke patients were invited via internal communication within SARAH, a network that has nine rehabilitation centres throughout Brazil. Invited DHP included rehabilitation physicians, psychologists and physical therapists. DHP were identified using a Dutch medical address book including contact information of most healthcare professionals in the Netherlands, across the country. Since the participating countries are geographically far apart from each other, it was esteemed unlikely that one person could receive both the Brazilian and Dutch invitation, but this is not impossible. All eligible healthcare professionals (both Brazilian and Dutch) received an invitation email including a link to the online survey, in Dutch to the DHP (June 2017) and in Portuguese to the DHP (October 2017). Non-responders received two reminders, first after two weeks and second after four weeks that and the survey was available for five months.

\section{Survey development and content}

To develop the survey, eight focus groups were organized with both patients/informal caregivers and healthcare professionals (details about the analysis and results are published elsewhere (24)). Focus groups were used to collect a broad spectrum of possible factors influencing the use of eRehabilitation, including attitudes, experiences and expectations of the healthcare professionals (34). In this, eRehabilitation is the use of ICT to deliver conventional rehabilitation care and can be used to support therapy related activities, like physical and cognitive exercises, education and communication. Thirteen DHP working in stroke rehabilitation participated, including rehabilitation physicians $(n=4,31 \%)$, physical therapists $(n=3,23 \%)$, occupational therapists $(n=3,23 \%)$, psychologists $(n=1,8 \%)$, speech therapists $(n=1,8 \%)$, and managers $(n=1,8 \%)$.

All focus groups were audiotaped and transcribed in full in Dutch. The transcripts were qualitatively analysed using directed content analysis, in which the researchers used a theory or relevant research findings as guidance for initial code (35), in this case the implementation model of Grol and Wensing (36). This model was chosen because it provides a framework for identifying and categorizing factors that influence the use of innovations in healthcare (36). A total of 88 barriers/facilitators that impact the use of eRehabilitation were identified. Those were grouped into fourteen factors, divided at five levels of Grol (see Table 1); the innovation (e.g. content of eRehabilitation, feasibility, accessibility), the organisational context (e.g. tasks and responsibilities of involved end-users, time and resources), the individual patient (skills, knowledge, motivation the change and patient characteristics), the individual professional (skill, knowledge, motivation to change) and the financial arrangements (e.g. insurance).

To prioritize all barriers/facilitators identified in the focus groups, a survey was conducted in the Netherlands (June 2016) and Brazil (December 2017). The survey included questions about personal characteristics and statements about barriers/facilitators influencing the use of eRehabilitation.

Socio-demographic-, disease- and work-related characteristics: The survey started with the question 'Are you working with stroke patients?' If not, the survey was ended. If 'yes', 12 questions followed regarding age, gender, work setting (primary care/rehabilitation centre/general hospital), years of work experience, number of new stroke patients per month and their current use of eRehabilitation (no, yes; if yes: exercises/games/information).

Influencing barriers/facilitators: Each potential barrier/facilitator identified in the focus group study was translated into a neutral statement. A total of 88 statements were formulated based on the transcripts of the focus groups (see additional file 1). The influence for the use eRehabilitation of each statement was rated on a 4-point Likert scale (1=unimportant, 2=somewhat unimportant, 3 =somewhat important, 4=important or 1=disagree, $2=$ partly disagree, $3=$ partly agree, 4=agree).

The survey was tested in a pilot among three DHP (2 males, 2 physical therapists, 1 occupational therapist, mean age 38 years old, mean working experience 13.3 years). The survey was tested for feasibility, legibility, readability and presentation (e.g., perceived statement difficulty, response errors, etc.). Testing led to small changes in the phrasing and layout.

The survey was based on the results focus groups in the Netherlands and developed in Dutch. For the BHP, the survey was translated by a qualified Portuguese-language translator. First, the Dutch version was translated into English by the translation 
agency Attached Language and the translation was discussed in the project team leading to minor changes. Subsequently, the English version was translated into Portuguese and was tested by two Portuguese project members. Differences were discussed and adaptations were made in three rounds until the Portuguese questionnaire was similar to the original Dutch version.

\section{Data analysis}

Participants who completed $>90 \%$ of the survey were included in the analysis, which was executed using Statistical Packages for the Social Sciences (IBM SPSS 22.0), and no imputations were done for missing data. Personal characteristics were analysed using descriptive statistics. T-test or Pearson Chi-square test was used to compare age, gender, number of new patients, work experience and the use of eRehabilitation between BHP with DHP.

Based on the median score, all statements influencing the use of eRehabilitation were given a ranking (lowest number equals large influence), separately for the BHP and DHP. For the statements with a similar median, definite ranking was based on the mean. The top-ten most and least influencing statements were noted and differences in ranking were calculated to describe the level of agreement among DHP and BHP. The ranking of all statements for both the DHP and BHP were plotted on a scatterplot, including a $95 \%$ confidence interval (Cl). Additionally, these analyses were performed with only the disciplines included both in the Netherlands and Brazil (i.e. physical therapists, psychologists and physicians).

\section{Ethical issues and approval}

All participants gave written informed consent prior to participation. Data were collected and analysed anonymously. This study was approved by the Medical Ethical Review Board of the Leiden University Medical Centre [P15.281] and the Medical Ethics Board of SARAH Network of Rehabilitation Hospitals.

\section{Results}

\section{Study_population}

Of the 361 invited BHP, 331 were reached and 99 responded (response rate 30\%); of the 362 invited DHP, 288 were reached and 105 responded (response rate $37 \%)$. Thirty $(8.3 \%)$ of the BHP and $30(10 \%)$ DHP did not work with stroke patients and were therefore excluded from the analyses (see figure 1). Table 2 shows that BHP and DHP did not differ significantly in age (40.0 (SD 6.4) and 42.0 (SD 10.5) years old, respectively), gender ( $n=21(21 \%)$ and $n=25(24 \%)$ male, respectively), work experience (15.6 (SD6.2) and 14 (SD10) years, respectively) and previous use of eRehabilitation ( $n=50(50 \%)$ and $n=40(38 \%)$ respectively). BHP had significantly more new patients each month compared to the DHP $(p=0.00)$. DHP included physical therapists $(n=41,39 \%)$, psychologists $(n=14,13 \%)$ and physicians $(n=47,45 \%)$, BHP included physical therapists $(n=14,14 \%)$, psychologists $(n=12,12 \%)$, physicians $(n=10,10 \%)$; additionally, nurses $(n=28,26 \%)$, hospital educators $(n=3,3 \%)$, physical education teachers $(n=10,10 \%)$ and neurologists $(n=5,5 \%)$ were included in the BHPs.

\section{Most and least influencing statements}

Table 3a and $3 \mathrm{~b}$ show the ten most and ten least influencing statements for DHP and BHP to use eRehabilitation after stroke. In the top-10 most influencing factors, four statements were found for both BHP and of DHP, and twelve statements were found in the top-10 of only one group (see table 3a). The six statements found for only BHP were related to the factor Patient Motivation to Change (i.e., improved therapy adherence and health outcomes) and the Organization of Care (i.e., sufficient time and support from the organization); the six statements found for only DHP were mostly related to the factor Feasibility of eRehabilitation (like a helpdesk and support).

On the other hand, the statements that BHP and DHP considered not influencing the use of eRehabilitation were comparable, with eight statements found in the top-10 of BHP and DHP. Factors that did not influence eRehabilitation use were related to the factor Patient characteristics (i.e., cognitive and physical disability or aphasia) and the factor Resources (i.e., problems with the internet 
connection or hard- and software).

The abovementioned analyses were also performed including only the disciplines that were represented in both countries (i.e. physical therapists, rehabilitation physicians and psychologists), resulting in comparable findings. Only the two statements 'Problems with the devices on which eRehabilitation is used and 'Problems with the internet connection' were not found in the topten least influencing statements of this sub-analysis; the top-ten most influencing statements was fully comparable with the results of the all respondents (see table $3 a$ and $3 b$ ).

Difference and similarities in ranking

The difference in ranking for the BHP and DHP was calculated for each statement (see additional file 1). The mean absolute difference in ranking between BHP and DHP was 11.2 (SD 15.9, range 0-58). In figure 2, the ranking of the Brazilian responses is plotted against the Dutch responses. Four statements were found outside the $95 \% \mathrm{Cl}$. BHP reported the following statements more frequently as important than DHP: 1) 'The eRehabilitation program is accessible offline', 2) 'Exercises to train cognitive functioning' and 3). 'eRehabilitation is used by the entire multidisciplinary team'. DHP reported the following statement more frequently as important than BHP: 'Decisions made during a consult are documented and visible for patients.' Two of those statements (the second and fourth) were found in the top-10 most influencing statements of respectively BHP and DHP (see Table 3a).

For the majority of the factors, the statements constituting that factor were spread out on a broad range of the scatterplot, with at least one statement within the 20 most and one statement in the 20 least influencing statements (see also additional file 1 and figure 2). Only the statements constituting the factors Resources, Patient Motivation not to change and Patient characteristics were found only with a low influence.

\section{Discussion}

In this study, we investigated differences and similarities in factors influencing the use of eRehabilitation after stroke among healthcare professionals from Brazil and the Netherlands. The statements with the highest influence on the use of eRehabilitation differed between BHP and DHP; BHP agreed more with factors related to the benefits for the patients and organizational constrains, DHP agreed more with factors related to the feasibility of the use of eRehabilitation. The statements with the least influence on the use of eRehabilitation were comparable for BHP and DHP, and were related to patient characteristics and resources. This means that BHP and DHP indicate that the use of eRehabilitation is influenced by different factors and tailored implementation strategies for both countries need to be developed separately (16).

For BHP, and with a lesser frequency for DHP, the factor Motivation to change was important. Benefits of the use of eRehabilitation were found important before, including the possibility to train at home (37), independently continue therapy activities (4) and easily accessible contact with a healthcare professionals after discharge or during outpatient therapy $(12,13)$. For BHP, time and support for the healthcare professional from the organization is also important. Facilitating conditions, including time, communication and education, was found to be an important facilitating factor in the use of eRehabilitation after stroke before $(13,38)$. For DHP, a thorough helpdesk delivering support for patients and healthcare professional is crucial. This is in line with a review of Pugliese (2018) concluding that the most reported patient barrier was following instructions about how to use the device (39).

Concerning the content of the eRehabilitation intervention, for the BHP speech and cognitive exercisers are important, were the DHP focus on physical exercises, and offline accessibility seems important in Brazil but not in the Netherlands. For the DHP it is important that decisions that were made during a consult are incorporated in the eRehabilitation intervention. Therefore it can be concluded that not only the implementation strategy should be adapted to the wishes of the end-users (12), but also the eRehabilitation intervention. 
Most factors were constructed of statements that were spread over a broad ranking and included both statements influencing and non-influencing the use of eRehabilitation. So some differences might remain hidden at factor level, since statements within a factor compensate for each other, differences can be found at statement levels. Therefore, it is important to investigate barriers/facilitators for the implementation of eRehabilitation in detail rather than on the level over overarching factors.

Although our study revealed some important differences and similarities among Brazilian and Dutch healthcare professionals, the results have to be interpreted with care due to some limitations. First, only $36 \%$ of the BHC were physical therapists, psychologists and rehabilitation physicians; i.e. the disciplines invited in the Netherlands. However, when only the responses of the Brazilian physical therapists, psychologists and rehabilitation physicians were taken into account, the results of the analyses were comparable with the results of all BHPs. Therefore, it seems plausible that differences are caused by the various contexts and not by the specific professional backgrounds of the respondents. Second, the response rate of $30-37 \%$ in our study may have led to response bias because those who responded to the invitation to participate in the survey were probably more interested in eRehabilitation. As a consequence, the perspective of end-users with less interest in and experience with eRehabilitation might be missing. A third limitation is that the survey statements were based on the results of focus groups performed in the Netherlands. Consequently, we might have missed factors influencing the use of rehabilitation in Brazil that are not present in the Netherlands. However, the developed survey covered all levels of the framework of Grol and showed high amount of saturation (e.g. for two consecutive focus groups, no new factors were found), which reduces the chance of missing potentially important factors. At last, the generalizability of our results beyond the Netherlands and Brazil may be limited. The countries involved differed a lot on important factors (e.g. income and demographics), which is crucial for the development of a successful implementation strategy. It may be assumed that other counties will differ as well, which should be further investigated.

\section{Conclusion}

Important differences were found in factors influencing the use of eRehabilitation after stroke between BHP and DHP. For BHP, the use of eRehabilitation after stroke was most influenced by support from the rehabilitation organization and the potential benefits of the use of eRehabilitation. For DHP, the feasibility of the use of eRehabilitation for the patient was most influential. Implementation strategies should incorporate those differences, including an eRehabilitation intervention adapted to the wishes of the end-users. Statements with low influence, such as problems caused by patient characteristics after stroke or problems with resources, were comparable for both groups and should have less priority in the implementation strategies. More research about differences between disciplines in Brazil and the generalizability of those results for other countries is needed.

\section{List Of Abbreviations}

ICT; information and communication technology

BHP; Brazilian healthcare professionals

DHP; Dutch healthcare professionals

\section{Declarations}

\section{Ethics approval and consent to participate}

All participants gave written informed consent prior to participation. The study was approved by the Medical Ethical Review Board of the Leiden University Medical Center [P15.281].

\section{Consent for publication}

Not applicable.

\section{Availability of data and material}

The datasets used and/or analysed during the current study are available from the corresponding author on reasonable request. 


\section{Competing interests}

The authors declare that they have no competing interests.

\section{Funding}

Stichting Innovatie Alliantie supported this project financially (Grant 2014-046PRO).

\section{Authors' contributions}

BB conducted the focus groups and the survey in the Netherlands, and analysed the data. LBV, JM and TVV were a major contributor in writing the manuscript. AK contributed to the cooperation between the Netherlands and Brazil. IG, LS and LB conducted the survey in Brazil. All authors read and approved the final manuscript.

\section{Acknowledgement}

We would like to thank all healthcare professionals in Brazil and the Netherlands who participated in the survey.

\section{References}

(1) Pandian JD, William AG, Kate MP, Norrving B, Mensah GA, Davis S, et al. Strategies to Improve Stroke Care Services in Low- and Middle-Income Countries: A Systematic Review. Neuroepidemiology 2017;49(1-2):45-61.

(2) Krpic A, Savanovic A, Cikajlo I. Telerehabilitation: remote multimedia-supported assistance and mobile monitoring of balance training outcomes can facilitate the clinical staff's effort. Int J Rehabil Res 2013 Jun;36(2):162-171.

(3) Murray CJ, Vos T, Lozano R, Naghavi M, Flaxman AD, Michaud C, et al. Disability-adjusted life years (DALYs) for 291 diseases and injuries in 21 regions, 1990-2010: a systematic analysis for the Global Burden of Disease Study 2010. Lancet 2012 Dec 15;380(9859):2197-2223.

(4) Russel TG. Telerehabilitation: a coming of age. Australian Journal of Physiotherapy 2009;55(1):5-6.

(5) Laver KE, Schoene D, Crotty M, George S, Lannin NA, Sherrington C. Telerehabilitation services for stroke. Cochrane Database Syst Rev 2013 Dec 16;16(12):CD010255.

(6) Webster D, Celik O. Systematic review of Kinect applications in elderly care and stroke rehabilitation. Journal of neuroengineering and rehabilitation, 2014;11(1):108.

(7) Schwamm, L. H., Chumbler, N., Brown, E., Fonarow, G.C., Berube D, Nystrom K, Lacktman N. Recommendations for the Implementation of Telehealth in Cardiovascular and Stroke Care: A Policy Statement From the American Heart Association. Circulation 2017;135(7):24-44.

(8) Johansson T, Wild C. Telerehabilitation in stroke care--a systematic review. J Telemed Telecare 2011;17(1):1-6.

(9) Karasu AU, Batur EB, Karatas GK. Effectiveness of Wii-based rehabilitation in stroke: A randomized controlled study. J Rehabil Med 2018 May 8;50(5):406-412.

(10) Pugliese M, Ramsay T, Johnson D, Dowlatshahi D. Mobile tablet-based therapies following stroke: A systematic scoping review of administrative methods and patient experiences. PLoS One 2018 Jan 23;13(1):e0191566.

(11) Winters JM. Telerehabilitation research: emerging opportunities. Annu Rev Biomed Eng 2002;4:287-320.

(12) Hochstenbach-Waelen A, Seelen HA. Embracing change: practical and theoretical considerations for successful implementation of technology assisting upper limb training in stroke. J Neuroeng Rehabil 2012 Aug 2;9:52-64. 
(13) Davoody N, Hagglund M. Care Professionals' Perceived Usefulness of eHealth for Post-Discharge Stroke Patients. Stud Health Technol Inform 2016;228:589-593.

(14) Sarfo FS, Adamu S, Awuah D, Sarfo-Kantanka O, Ovbiagele B. Potential role of tele-rehabilitation to address barriers to implementation of physical therapy among West African stroke survivors: A cross-sectional survey. J Neurol Sci 2017 Oct 15;381:203-208.

(15) Sarfo FS, Ulasavets U, Opare-Sem OK, Ovbiagele B. Tele-Rehabilitation after Stroke: An Updated Systematic Review of the Literature. J Stroke Cerebrovasc Dis 2018 Sep;27(9):2306-2318.

(16) Miranda JJ, Moscoso MG, Yan LL, Diez-Canseco F, Malaga G, Garcia HH, et al. Addressing post-stroke care in rural areas with Peru as a case study. Placing emphasis on evidence-based pragmatism. J Neurol Sci 2017 Apr 15;375:309-315.

(17) Wachter RM. Making IT work: harnessing the power of health information technology to improve care in England. 2016.

(18) Edgar MC, Monsees S, Rhebergen J, Waring J, Van der Star T, Eng JJ, et al. Telerehabilitation in Stroke Recovery: A Survey on Access and Willingness to Use Low-Cost Consumer Technologies. Telemed J E Health 2017 Oct 5;23(5):421-429.

(19) McCluskey A, Vratsistas-Curto A, Schurr K. Barriers and enablers to implementing multiple stroke guideline recommendations: a qualitative study. BMC Health Serv Res 2013 Aug 19;13:323-336.

(20) White J, Janssen H, Jordan L, Pollack M. Tablet technology during stroke recovery: a survivor's perspective. Disabil Rehabil 2015;37(13):1186-1192.

(21) Yan LL, Li C, Chen J, Miranda JJ, Luo R, Bettger J, et al. Prevention, management, and rehabilitation of stroke in low- and middle-income countries. eNeurologicalSci 2016 Mar 2;2:21-30.

(22) Brouns B, Meesters JJL, Wentink MM, de Kloet AJ, Arwert HJ, Boyce L, et al. Factors associated with willingness to use eRehabilitation after stroke: A cross-sectional study among patients, informal caregivers and healthcare professionals. J Rehabil Med 2019 Aug 15.

(23) Lo EC, Tan HP. Cultural challenges to oral healthcare implementation in elders. Gerodontology 2014 Feb;31 Suppl 1:72-76.

(24) Brouns B, Meesters JJL, Wentink MM, de Kloet AJ, Arwert HJ, Vliet Vlieland TPM, et al. Why the uptake of eRehabilitation programs in stroke care is so difficult-a focus group study in the Netherlands. Implement Sci 2018 Oct 29;13(1):133-018-0827-5.

(25) Tong A, Sainsbury P, Craig J. Consolidated criteria for reporting qualitative research (COREQ): a 32-item checklist for interviews and focus groups. Int J Qual Health Care 2007 Dec;19(6):349-357.

(26) Brazil Ministry of Health. Ministry of Health. Stroke Care Line in the emergency and emergency care network. 2012; Available at: http://portal.saude.gov.br/portal/arquivos/pdf/linha_cuidado_avc_rede_urg_emer.pdf >. Accessed April, 2019.

(27) Brazil MoH. Guidelines for attention to rehabilitation of the person with stroke. 2013.

(28) CBS. . 2017; Available at: (25) CBS. 2017; Available at: https://www.volksgezondheidenzorg.info/onderwerp/beroerte/cijferscontext/sterfte\#bron-node-tabel-bronnen-bij-de-cijfers-over-beroerte.

(29) Kunst AE, Amiri M, Janssen F. The decline in stroke mortality: exploration of future trends in 7 Western European countries. Stroke 2011 Aug;42(8):2126-2130.

(30) Feigin VL, Norrving B, Mensah GA. Global Burden of Stroke. Circ Res 2017 Feb 3;120(3):439-448.

(31) Stroke Guidelines. www.zorginzicht.nl/bibliotheek/acuteberoertezorg/registerKwaliteitsstandaardenDocumenten/conceptversie\%20Richtlijn\%20Herseninfact\%20en\%20hersenbloeding.pdf. 
(32) Groeneveld IF, Meesters JJ, Arwert HJ, Roux-Otter N, Ribbers GM, van Bennekom CA, et al. Practice variation in the structure of stroke rehabilitation in four rehabilitation centres in the Netherlands. J Rehabil Med 2016 Mar;48(3):287-292.

(33) Bots ML, Buddeke J, van Dis I, Vaartjes I, Visseren FLJ. Hart- en vaatziekten in Nederland 2017. Cijfers over leefstijl, risicofactoren, ziekte en sterfte. 2017.

(34) Kitzinger J. Focus groups. In: Pope C, Mays N, editors. Qualitative research in health care. 3rd ed. Malden: Blackwell publishing; 2006. p. 21-31.

(35) Hsieh HF, Shannon SE. Three approaches to qualitative content analysis. Qual Health Res 2005 Nov;15(9):1277-1288.

(36) Grol R, Wensing M. What drives change? Barriers to and incentives for achieving evidence-based practice. Med J Aust 2004 Mar 15;180(6):57-60.

(37) Palmcrantz S, Borg J, Sommerfeld D, Plantin J, Wall A, Ehn M, et al. An interactive distance solution for stroke rehabilitation in the home setting - A feasibility study. Inform Health Soc Care 2017 Sep;42(3):303-320.

(38) Nguyen AV, Ong YA, Luo CX, Thuraisingam T, Rubino M, Levin MF, et al. Virtual reality exergaming as adjunctive therapy in a sub-acute stroke rehabilitation setting: facilitators and barriers. Disabil Rehabil Assist Technol 2018 Mar 12:1-8.

(39) Pugliese M, Johnson D, Dowlatshahi D, Ramsay T. Mobile tablet-based therapies following stroke: a systematic scoping review protocol of attempted interventions and the challenges encountered. Syst Rev 2017 Nov 2;6(2):219-226.

\section{Tables}

Table 1: results of focus groups; factors influencing the use of eRehabilitation (2 focus groups)

\begin{tabular}{|c|c|c|}
\hline Level & Factor & Sub-factor \\
\hline \multirow[t]{7}{*}{ Innovation } & Accessibility & $\begin{array}{l}\text { Time frame in which eRehabilitation is accessible } \\
\text { Devices on which eRehabilitation is accessible }\end{array}$ \\
\hline & Feasibility & Helpdesk function \\
\hline & & Tailored to patients' situation \\
\hline & Attractiveness & Ease of use of eRehabilitation \\
\hline & & Content of eRehabilitation program \\
\hline & Privacy & Privacy and safety of patient data \\
\hline & Advantages of use & Added value of innovation offered \\
\hline \multirow[t]{5}{*}{ Organizational context } & Organization of care & $\begin{array}{l}\text { Tasks and responsibilities healthcare professional } \\
\text { Tasks and responsibilities informal caregiver }\end{array}$ \\
\hline & & Tasks and responsibilities organization \\
\hline & Resources & Software \\
\hline & & Hardware \\
\hline & Time & Time \\
\hline \multirow[t]{3}{*}{ Individual patients } & Motivation to change & Reasons to use eRehabilitation for patients \\
\hline & Motivation not to change & Reasons not to use eRehabilitation for patients \\
\hline & Patient characteristics & Impairments after stroke \\
\hline \multirow[t]{2}{*}{ Individual professional } & Motivation to change & Reasons to use eRehabilitation \\
\hline & Motivation not to change & Reasons not to use eRehabilitation \\
\hline Economic \& political context & Financial arrangements & Insurance \\
\hline
\end{tabular}


Table 2: Characteristics of Brazilian and Dutch healthcare professionals participating in the survey study

\begin{tabular}{lcc}
\hline Characteristics & BHP $(\mathrm{n}=99)$ & DHP $(\mathrm{n}=105)$ \\
\hline Age, years (mean, SD) & $40.0(6.4)$ & $42.0(10.5)$ \\
Sex, (n male, \%) & $21(21)$ & $25(24)$ \\
\hline Work experience, years (mean, SD) & $15.6(6.2)$ & $14.0(10.0)$ \\
\hline Number of new patients per month (mean, SD) & $13.5(9.5)$ & $8.0(8.9)$ \\
\hline Discipline, (n, \%) & & \\
\hline Physical therapist & $14(14)$ & $41(39)$ \\
\hline Psychologist & $12(12)$ & $14(13)$ \\
\hline Physician & $10(10)$ & $47(45)$ \\
\hline Nurse & $28(26)$ &. \\
\hline Occupational therapist & $3(3)$ &. \\
\hline Hospital-based educator & $3(3)$ &. \\
\hline Physical education instructor & $10(10)$ &. \\
\hline Neurologist & $5(5)$ & $3(3)$ \\
\hline Other* & $14(14)$ & \\
\hline Work setting** (n, \%) & & $10(10)$ \\
\hline Health centre in primary care &. & $75(71)$ \\
\hline Rehabilitation centre & $97(97)$ & $34(32)$ \\
\hline Hospital & $4(4)$ & $40(38)$ \\
\hline Use of digital rehabilitation tools (n yes, \%) & $50(50)$ &. \\
\hline B
\end{tabular}

BHP; Brazilian healthcare professional, DHP; Dutch healthcare professional

In bold significant differences between BHP and DHP ( $p$-value $=0.00$ )

* Occupational therapist, Speech therapist, Nutritionist, Social worker, **Multiple answers possible

Table 3a: statements with the most influence on the use of eRehabilitation

\begin{tabular}{|c|c|c|c|c|c|c|}
\hline \multirow[t]{2}{*}{$\begin{array}{l}\text { Statement } \\
\text { I would use e-rehabilitation, if... }\end{array}$} & \multirow[t]{2}{*}{ Factor } & \multirow[t]{2}{*}{$\begin{array}{c}\text { Barrier/ } \\
\text { facilitator }\end{array}$} & \multicolumn{2}{|c|}{ Brazil (n=99) } & \multicolumn{2}{|c|}{$\begin{array}{l}\text { Netherlands } \\
(\mathrm{n}=105)\end{array}$} \\
\hline & & & $\begin{array}{l}\text { Median } \\
\text { (IQR) }\end{array}$ & Ranking & $\begin{array}{l}\text { Median } \\
(\mathrm{IQR})\end{array}$ & Ranking \\
\hline It contributes to the patient's therapy compliance & $\begin{array}{l}\text { Patient motivation to } \\
\text { change }\end{array}$ & F & $4(4-4)^{*}$ & 1 & $4(4-4)$ & 8 \\
\hline eRehabilitation has a positive influence on recovery & $\begin{array}{l}\text { Patient motivation to } \\
\text { change }\end{array}$ & $\mathrm{F}$ & $4(4-4)^{*}$ & 2 & $4(4-4)$ & 2 \\
\hline $\begin{array}{l}\text { I can tailor the content of eRehabilitation to the patient's } \\
\text { personal situation }\end{array}$ & Feasibility & $\mathrm{F}$ & $4(4-4)^{*}$ & 3 & . & 12 \\
\hline I have time to (learn to) use eRehabilitation & Organization of care & $\mathrm{F}$ & $4(4-4)^{*}$ & 4 & . & 21 \\
\hline $\begin{array}{l}\text { I feel supported from within the organization to use } \\
\text { eRehabilitation }\end{array}$ & Organization of care & $\mathrm{F}$ & $4(4-4)^{*}$ & 5 & . & 32 \\
\hline $\begin{array}{l}\text { eRehabilitation offers a way to independently } \\
\text { continue therapy after discharge }\end{array}$ & $\begin{array}{l}\text { Patient motivation to } \\
\text { change }\end{array}$ & F & $4(4-4)^{*}$ & 6 & . & 15 \\
\hline ICT-problems are solved directly & Organization of care & $\mathrm{F}$ & $4(4-4)^{*}$ & 7 & $4(4-4)$ & 7 \\
\hline Logging on is easy & Accessibility & $\mathrm{F}$ & $4(4-4)^{*}$ & 8 & $4(4-4)$ & 3 \\
\hline My patient wants to use eRehabilitation & $\begin{array}{l}\text { Patient motivation to } \\
\text { change }\end{array}$ & $\mathrm{F}$ & $4(4-4)^{*}$ & 9 & $\cdot$ & 11 \\
\hline Exercises to train cognitive functioning ${ }^{\#}$ & Attractiveness & $\mathrm{F}$ & $4(4-4)^{*}$ & 10 & . & 55 \\
\hline A helpdesk is available for patients & Feasibility & $\mathrm{F}$ & . & 13 & $4(4-4)$ & 1 \\
\hline $\begin{array}{l}\text { Video instructions on how to use e-rehabilitation are } \\
\text { available for patients }\end{array}$ & Feasibility & $\mathrm{F}$ & . & 17 & $4(4-4)$ & 4 \\
\hline A menu with frequently asked questions (FAQ) for patients & Feasibility & $\mathrm{F}$ & . & 21 & $4(4-4)$ & 5 \\
\hline The patient can read information about stroke & Feasibility & $\mathrm{F}$ & . & 19 & $4(4-4)$ & 6 \\
\hline $\begin{array}{l}\text { Decisions made during a consult are documented and } \\
\text { visible for patients }{ }^{\#}\end{array}$ & Advantage of Use & $\mathrm{F}$ & . & 67 & $4(4-4)$ & 9 \\
\hline Insights in goals that are achieve & Attractiveness & $\mathrm{F}$ & . & 24 & $4(3-4)$ & 10 \\
\hline
\end{tabular}


Table 3b: statements with the least influence on the use of eRehabilitation

\begin{tabular}{|c|c|c|c|c|c|c|}
\hline \multirow[t]{2}{*}{$\begin{array}{l}\text { Statement } \\
\text { [ would not use e-rehabilitation, if... }\end{array}$} & \multirow[t]{2}{*}{ Factor of Grol } & \multirow[t]{2}{*}{$\begin{array}{c}\text { Barrier/ } \\
\text { facilitator }\end{array}$} & \multicolumn{2}{|c|}{ Brazil $(n=99)$} & \multicolumn{2}{|c|}{$\begin{array}{l}\text { Netherlands } \\
(n=105)\end{array}$} \\
\hline & & & $\begin{array}{l}\text { Median } \\
\text { (IQR) }\end{array}$ & Ranking & $\begin{array}{l}\text { Median } \\
\text { (IQR) }\end{array}$ & Ranking \\
\hline The patient has too many physical disabilities after stroke & Patient characteristic & B & $2(1-2)^{*}$ & 88 & $1(1-2)$ & 88 \\
\hline The patient has too much aphasia after stroke & Patient characteristic & B & $2(1-2)^{*}$ & 87 & $2(1-2)$ & 87 \\
\hline [ believe that there will be problems with software & Resources & $\mathrm{B}$ & $2(1-3)^{*}$ & 86 & $\cdot$ & 76 \\
\hline $\begin{array}{l}\text { There is too little scientific evidence for the effectiveness } \\
\text { Jf eRehabilitation }\end{array}$ & $\begin{array}{l}\text { Professional motivation } \\
\text { not to change }\end{array}$ & B & $2(1-3)^{*}$ & 85 & $2(2-3)$ & 82 \\
\hline $\begin{array}{l}\text { [mplementation of eRehabilitation } \\
\text { simultaneously with other ICT projects }\end{array}$ & Organization of care & $\mathrm{B}$ & $2(2-3)^{*}$ & 84 & . & 74 \\
\hline The patient has too many cognitive disabilities after stroke & Patient characteristic & $\mathrm{B}$ & $2(2-3)^{*}$ & 83 & $2(2-3)$ & 85 \\
\hline The patient has visual problems & Patient characteristic & $\mathrm{B}$ & $2(2-3)^{*}$ & 82 & $2(2-3)$ & 80 \\
\hline $\begin{array}{l}\text { Problems with the devices on which eRehabilitation is } \\
\text { ased }\end{array}$ & Resources & B & $3(1-4)$ & 81 & $3(1-3)$ & 79 \\
\hline Problems with the internet connection & Resources & $\mathrm{B}$ & $3(1-4)$ & 80 & $3(1-3)$ & 81 \\
\hline $\begin{array}{l}\text { The patient cannot compare his/her results with the } \\
\text { scores of other stroke patients }\end{array}$ & Attractiveness & $\mathrm{F}$ & $3(2-3)^{*}$ & 79 & $2(1-3)$ & 86 \\
\hline $\begin{array}{l}\text { [ cannot compare patients results with the scores of other } \\
\text { stroke patients }\end{array}$ & Attractiveness & $\mathrm{F}$ & . & 74 & $2(2-3)$ & 84 \\
\hline $\begin{array}{l}\text { The healthcare professional contacts the patients if he/she } \\
\text { sxercises too little }\end{array}$ & Organization of care & $\mathrm{F}$ & . & 70 & $2(2-3)$ & 83 \\
\hline
\end{tabular}

= no part of least influencing statements, B; barrier, F; facilitator, IQR; Interquartile range

${ }^{k}$ In the top-ten when only physical therapists, rehabilitation physicians and psychologist are included

\section{Figures}


BHP invited to participate $(n=361)$

DHP invited to participate $(\mathrm{n}=362)$

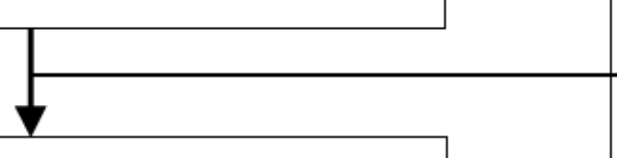

BHP reached $(n=331)$

DHP reached $(\mathrm{n}=288)$

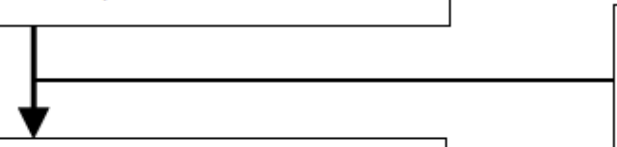

BHP who responded to the questionnaire $(\mathrm{n}=106)$

DHP who responded to the questionnaire $(\mathrm{n}=129)$
BHP; Non-responders $(\mathrm{n}=225)$

DHP; Non-responders $(\mathrm{n}=159)$

$B H P$ : No involvement in stroke $(\mathrm{n}=30)$

DHP: No valid email address $(\mathrm{n}=10)$, Absent $(\mathrm{n}=34)$, No involvement in stroke $(\mathrm{n}=30)$

$B H P$ : Incomplete questionnaires $(\mathrm{n}=7)$

$D H P$ : Incomplete questionnaires $(\mathrm{n}=24)$

Completed questionnaires DHP $(\mathrm{n}=105)$

Figure 1

Flowchart 


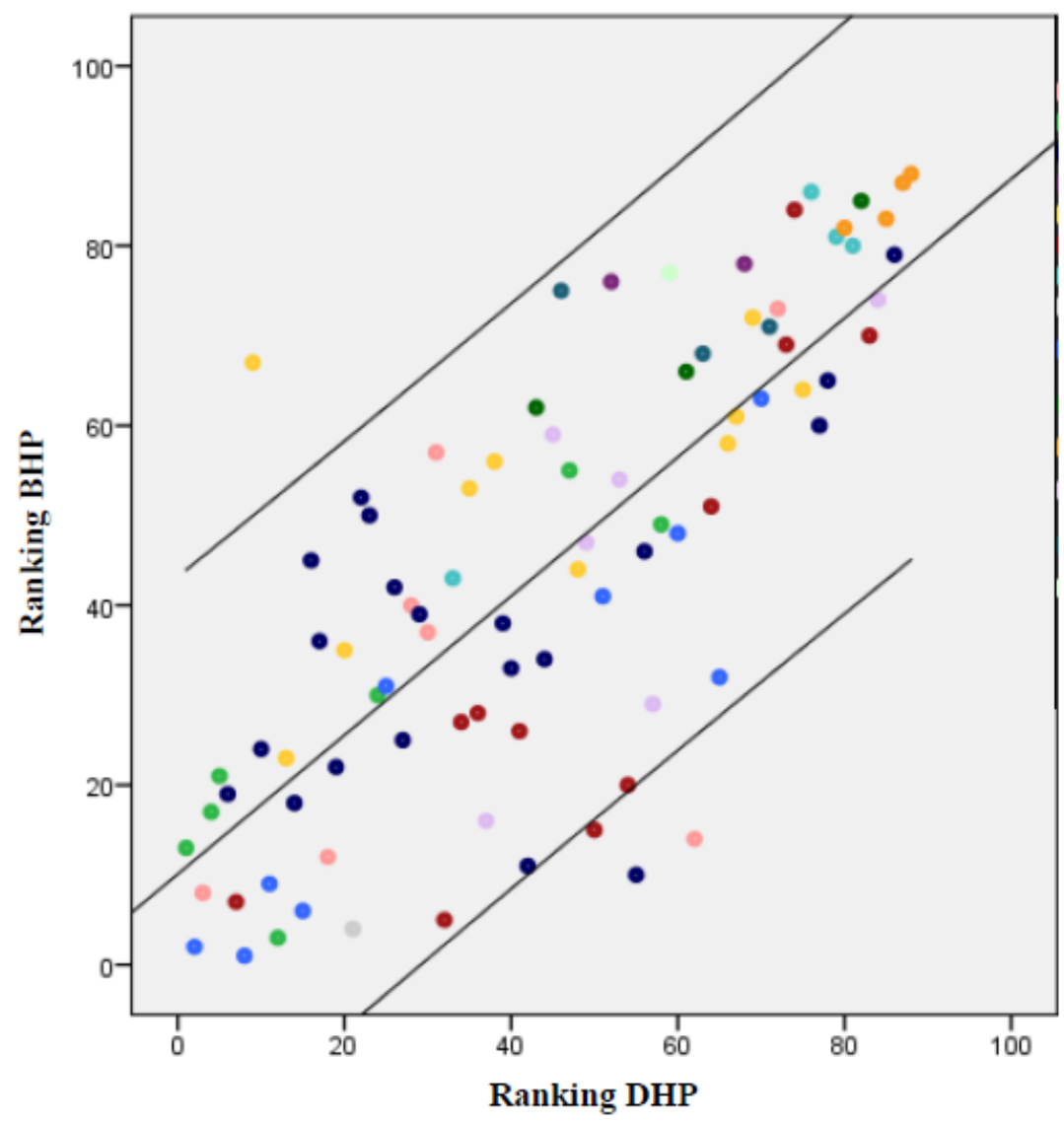

Legend figure 2

Accessibility

Feasibility

- Attractiveness

Privacy

Advantages of use

- Organization of care

Resources

Time

D Patient motivation to change

D Patient motivation not to change

Patient characteristics

b. Professional motivation to change

p Professional not motivation to change

: Financial arrangements

Figure 2

Scatterplot of the ranking of all statements for the Brazilian healthcare professionals (BHP) and Dutch healthcare professionals (BHP). Lower values are statements with more influence.

\section{Supplementary Files}

This is a list of supplementary files associated with this preprint. Click to download.

- Additionalfile2STROBEchecklist.pdf

- Additionalfile1.pdf 